\title{
Programmed and Induced Phenotype of the Hippocampal Granule Cells
}

\author{
Gisela Gómez-Lira, ${ }^{1}$ Mónica Lamas, ${ }^{2}$ Héctor Romo-Parra, ${ }^{1}$ and Rafael Gutiérrez ${ }^{1}$ \\ ${ }^{1}$ Departamento de Fisiología, Biofísica y Neurociencias, Centro de Investigación y de Estudios Avanzados, 07000 Distrito Federal, México, and 2Instituto de \\ Fisiología Celular, Universidad Nacional Autónoma de México, Ciudad Universitaria, 04510 Distrito Federal, México
}

Certain neurons choose the neurotransmitter they use in an activity-dependent manner, and trophic factors are involved in this phenotypic differentiation during development. Developing hippocampal granule cells (GCs) constitutively express the markers of the glutamatergic and GABAergic phenotypes, but when development is completed, the GABAergic phenotype shuts off. With electrophysiological, single-cell reverse transcription-PCR and immunohistological techniques, we show here that short-term ( $24 \mathrm{~h})$ cultures of fully differentiated adult glutamatergic GCs, which express glutamate, VGlut-1 (vesicular glutamate transporter) mRNA, calbindin, and dynorphin mRNA, can be induced to reexpress the GABAergic markers $\mathrm{GABA}, \mathrm{GAD}_{67}$ (glutamate decarboxylase $67 \mathrm{kDa}$ isoform), and VGAT (vesicular GABA transporter) mRNA, by sustained synaptic or direct activation of glutamate receptors and by activation of TrkB (tyrosine receptor kinase B) receptors, with brain-derived neurotrophic factor (BDNF) (30 min). The expression of the GABAergic markers was prevented by the blockade of glutamate receptors and sodium or calcium channels, and by inhibitors of protein kinases and protein synthesis. In hippocampal slices of epileptic rats and in BDNF-treated slices from naive rats, we confirmed the appearance of monosynaptic $\mathrm{GABA}_{\mathrm{A}}$ receptor-mediated responses to $\mathrm{GC}$ stimulation, in the presence of glutamate receptors blockers. Accordingly, GC cultures prepared from these slices showed the coexpression of the glutamatergic and GABAergic markers. Our results demonstrate that the neurotransmitter choice of the GCs, which are unique in terms of their continuing birth and death throughout life, depends on programmed and environmental factors, and this process is neither limited by a critical developmental period nor restricted by their insertion in their natural network.

Key words: granule cells; GABA; glutamate; VGlut-1 mRNA; VGAT mRNA; single-cell RT-PCR; phenotypic plasticity; BDNF

\section{Introduction}

The choice of a neurotransmitter by differentiating neurons has been related to neuronal identity and to extrinsic influences, whereby the regulation of this process has been shown to be homeostatic. In Xenopus laevis spinal cord, suppression of activity leads to an increased number of neurons expressing excitatory transmitters and a decreased number of neurons expressing inhibitory transmitters; the reverse occurs when activity is enhanced (Borodinsky et al., 2004). In the rodent developing dentate gyrus (DG), when the activation of GABA receptors and glutamate receptors (GluRs) needs to happen in synergy to activate NMDA receptors (Leinekugel et al., 1997), the granule cells (GCs) express a dual glutamatergic/GABAergic phenotype (Walker et al., 2001; Gutiérrez et al., 2003; Kasyanov et al., 2004). After this period, the GABAergic phenotype of the GCs shuts off (Gutiérrez et al., 2003), but the adult GCs still contain traces of

\footnotetext{
Received Nov. 2, 2004; revised June 2, 2005; accepted June 3, 2005.

This work was supported in part by Consejo Nacional de Ciencia y Tecnología Grant 36178-N, the Third World Academy of Sciences Grant 01-407, and Fundación Miguel Alemán A.C. (R.G.). The Alexander von Humboldt Foundation donated the Zeiss microscope used in our studies. We thank B. Muñoz for excellent technical support and Drs. B. Berninger, S. Marty, and M. Simonato for constructive discussions.

Correspondence should be addressed to Dr. Rafael Gutiérrez, Departamento de Fisiología, Biofísica y Neurociencias, Centro de Investigación y Estudios Avanzados, Apartado Postal 14-740, 07000 Distrito Federal, México. E-mail: grafael@fisio.cinvestav.mx.

DOI:10.1523/JNEUROSCI.1674-05.2005

Copyright $\odot 2005$ Society for Neuroscience $\quad 0270-6474 / 05 / 256939-08 \$ 15.00 / 0$
}

GABA and its synthesizing enzyme glutamate decarboxylase 67 $\mathrm{kDa}$ isoform $\left(\mathrm{GAD}_{67}\right)$ (Sandler and Smith, 1991; Sloviter et al., 1996). Interestingly, seizures or sustained excitation provoke a transient upregulation of $\mathrm{GABA}, \mathrm{GAD}_{67}$, and the vesicular GABA transporter (VGAT) mRNA (Schwarzer and Sperk, 1995; Lehmann et al., 1996; Sloviter et al., 1996; Lamas et al., 2001; Ramírez and Gutiérrez, 2001; Gómez-Lira et al., 2002; Gutiérrez, 2002; Bergersen et al., 2003). Under these conditions, the activation of GCs provokes, in addition to monosynaptic glutamatergic responses, monosynaptic GABAergic responses on pyramidal cells and interneurons of hippocampal area CA3. Moreover, the emergence of GABAergic transmission depends on protein synthesis (Gutiérrez, 2000, 2002; Gutiérrez and Heinemann, 2001; RomoParra et al., 2003).

Thus, adult GCs transiently upregulate their latent GABAergic phenotype in response to demanding conditions, and sustained or repeated depolarization seems to be a common determinant (Gutiérrez, 2002). But is it necessary for the GCs to be engaged in a hyperexcitable network to express this phenotypic plasticity? Is depolarization the only triggering event? Other candidate factors that can trigger this plasticity are brain-derived neurotrophic factor (BDNF) and GABA, which are released in an activitydependent manner in the DG. GABA itself constitutes a trophic signal in the hippocampus (Ben-Ari et al., 1994), and neurotrophins have a differentiating effect on interneurons in the hip- 
pocampus (Marty et al., 1996a,b) and cortex (Marty et al., 1997; Patz et al., 2003), in which they regulate the expression of GABAergic markers. Noteworthy, GCs contain BDNF and also possess the tyrosine receptor kinase $\mathrm{B}(\mathrm{TrkB})$ receptor.

Therefore, to gain insight into the determinants of phenotypic plasticity, we studied the effect of synaptic activation of the GCs, in situ, and the effect of activation of glutamate, GABA, and TrkB receptors, in vitro, on the determination of neurotransmitter choice in cultured adult GCs. By using electrophysiological, single-cell reverse transcription (RT)-PCR and immunohistological techniques, we show here that the choice of neurotransmitter in young GCs is programmed, whereas in adult GCs, it can be induced by external determinants, both in situ and in dissociated cultures. This suggests that phenotypic plasticity in GCs is neither limited by a critical developmental period nor restricted by their insertion in their natural network.

\section{Materials and Methods}

We used 15-d-old and adult Wistar rats. The latter were allocated into three groups: (1) control nonstimulated, (2) electrically kindled until at least five full blown seizures were provoked, and (3) intraperitoneally injected with the convulsant pentylenetetrazol (PTZ) $(60 \mathrm{mg} / \mathrm{kg}$; Sigma, St. Louis, MO) that provokes a single seizure. The kindling procedure was performed as described (Gutiérrez, 2000).

Hippocampal slice preparation and granule cell culture. Hippocampal slices (400 $\mu \mathrm{m}$ thick) were prepared as previously described (Gutiérrez, 2000) and incubated for $1 \mathrm{~h}$ in oxygenated artificial CSF (ACSF) containing the following (in mM): $120 \mathrm{NaCl}, 5 \mathrm{KCl}, 1 \mathrm{CaCl}_{2}, 2 \mathrm{MgCl}_{2}, 20 \mathrm{HEPES}$, 25 glucose, $\mathrm{pH} 7.35$, at room temperature $\left(21^{\circ} \mathrm{C}\right)$. They were then incubated for $15 \mathrm{~min}$ in ACSF containing $0.9 \mathrm{mg} / \mathrm{ml}$ trypsin (type XI; Sigma) and rinsed in ACSF (three times). The DG from two to three slices were dissected, and cells were mechanically dissociated in a total volume of 2 $\mathrm{ml}$ of ACSF with polished Pasteur pipettes of different diameters. Aliquots $(200 \mu \mathrm{l})$ of the cell suspension were placed over $1 \mathrm{~cm}^{2}$ coverslips treated with HistoGrip (Zymed, San Francisco, CA) and kept in culture wells in a $\mathrm{CO}_{2}$ incubator (NuAire, Plymouth, $\mathrm{MN}$ ) for $1 \mathrm{~h}$. The preparation medium was then substituted with $250 \mu$ l of culture medium consisting of the following: Neurobasal A (Invitrogen, Grand Island, NY) supplemented with horse serum (25\%; Invitrogen), penicillin/streptomycin ( $0.5 \%$; Invitrogen), and L-glutamine ( $0.5 \mathrm{~mm}$; Invitrogen). In some experiments (see Results), tetrodotoxin (TTX) (1 $\mu \mathrm{M}$; Sigma), (DL)2-amino-5-phosphonovaleric acid (APV) $(30 \mu \mathrm{M}$; Tocris Cookson, Ballwin, MO), and 6-nitro-7-sulfamoylbenzo(f)quinolaxine-2,3-dione (NBQX) (10 $\mu \mathrm{M}$; Tocris Cookson) were present in the preparation and culture media.

Treatment of the granule cells in vitro. Cells dissociated from the DG of young and adult naive rats were cultured for $24 \mathrm{~h}$ with or without TTX (see Results). After rinsing the cells three times with control culture medium, they were incubated for $30 \mathrm{~min}$ in culture medium containing the following: (1) kainic acid (KA) (5 $\mu \mathrm{M}$; Sigma), (2) KA in the presence of cycloheximide ( $5 \mu \mathrm{M}$; Sigma) or APV and NBQX, (3) GABA (50 $\mu \mathrm{M})$, with or without bicuculline (100 $\mu \mathrm{M}$; Sigma), (2S)-3[[(1S)-1-(3,4-dichlorophenyl)-ethyl]amino-2-hydroxypropyl](phenylmethyl)phosphinic acid hydrochloride (CGP55845A) (1 $\mu$ m; a gift from Novartis, New York, $\mathrm{NY}$ ), and nipecotic acid (1 mm; Sigma), (4) BDNF (100 ng/ml; a gift from Regeneron, Tarrytown, NY) (Li et al., 1998), with or without the Trk receptor inhibitors methyl-9-( $S)$-12( $R$ )-epoxy-1 $H$-diindolo[1,2,3-fg: 3'2' 1'-kl]pyrrolo[3,4-i][1,6]benzodiazocine-2,3,9,10,11,12-hexahydro-10( $R$ )-hydroxy-9-methyl-1-oxo-10-carboxilate (K252a) (500 nм; Sigma) or 1-(5-isoquinolinesulfonyl)-2-methylpiperazine (H7) (50 $\mu \mathrm{M}$; Sigma). Exposure of the cultures to BDNF was performed in serum-free medium. The cultures were kept in the $\mathrm{CO}_{2}$ incubator during and $3 \mathrm{~h}$ after their exposure to KA, GABA, and BDNF.

Electrophysiological recordings in slices. Combined entorhinal cortexhippocampus slices of control, kindled, and PTZ-treated rats were prepared and placed in an air-to-liquid interface recording chamber at $34 \pm$ $0.5^{\circ} \mathrm{C}$. Synaptic responses of CA3b pyramidal cells to DG activation were studied with standard electrophysiological techniques, as described previously (Gutiérrez, 2000). Additionally, slices of six naive rats were prepared, one-half of which were incubated in oxygenated ACSF containing BDNF (100 ng/ml) and one-half in BDNF plus K252a (500 nM) before the recordings commenced. The experimenter performed the intracellular recordings unaware of the origin of the slices or of the treatment to which they were subjected. The drugs used were diluted in the ACSF, namely, the NMDA receptor antagonist APV (30 $\mu \mathrm{M}$; Tocris Cookson), the nonNMDA receptor antagonist NBQX (10 $\mu \mathrm{M}$; Tocris Cookson), the GABA receptor antagonist bicuculline methiodide (20 $\mu \mathrm{M}$; Sigma), and the group III metabotropic GluR (mGluR) agonist $\mathrm{L}(+)$-2-amino-4phosphonobutyric acid (L-AP-4) (1 $\mu \mathrm{M}$; Tocris Cookson).

Electrophysiological recordings in cultures. The cultures were placed in an inverted microscope (Axiovert; Zeiss, Oberkochen, Germany) and recorded in the current-clamp mode of the whole-cell patch-clamp technique with an AxoPatch 200B amplifier (Molecular Devices, Palo Alto, $\mathrm{CA}$ ) bathed in a sterilized extracellular solution containing the following (in mM): $120 \mathrm{NaCl}, 5 \mathrm{KCl}, 1 \mathrm{CaCl} 2,1.5 \mathrm{MgCl} 2,25$ glucose, $20 \mathrm{HEPES} /$ $\mathrm{NaOH}$, at pH 7.4. Signals were filtered at $5 \mathrm{kHz}$, digitized (Digidata 1200; Molecular Devices), and analyzed with the program pClamp8 (Molecular Devices). We used Sigmacote-treated (Sigma) and sterilized borosilicate pipettes $(1.0 \mathrm{~mm}$ inner diameter; World Precision Instruments, Sarasota, FL) pulled to yield $3 \mathrm{M} \Omega$ (Flaming-Brown P-97 puller; Sutter Instrument Company, Novato, CA) and filled with sterile intracellular solution (5-8 $\mu \mathrm{l}$ ) containing the following (in $\mathrm{mm}$ ): $120 \mathrm{KCl}, 1 \mathrm{CaCl} 2,2$ $\mathrm{MgCl} 2,11.5$ EGTA, 10 HEPES, 20 glucose, at pH 7.4.

Single-cell RT-PCR. The cytosolic content of the recorded cells was extracted, applying gentle negative pressure with the recording pipette, and placed in a PCR tube containing the following: $8 \mu$ l of buffer $(5 \times)$ (One-Step RT-PCR kit; Qiagen, Valencia, CA), $1.6 \mu \mathrm{l}$ of dNTPs (final concentration, $10 \mathrm{~mm}$; One-Step RT-PCR kit; Qiagen), 50 pmol of each oligonucleotide, to amplify the selected RNAs (see below), $40 \mathrm{U}$ of RNase inhibitor (Invitrogen, Carlsbad, CA), and $3 \mu \mathrm{l}$ of the mixture of Omniscript reverse transcriptase, Sensiscript reverse transcriptase, and HotStarTaq DNA polymerase (One-Step RT-PCR kit; Qiagen), yielding a final volume of $40 \mu \mathrm{l}$. The RT-PCR was then performed in a thermocycler (PCR Express; Hybaid Limited, Ashford, UK) as follows: $30 \mathrm{~min}$ at $50^{\circ} \mathrm{C}, 15 \mathrm{~min}$ at $95^{\circ} \mathrm{C}, 30 \mathrm{~s}$ at $94^{\circ} \mathrm{C}, 30 \mathrm{~s}$ at $52^{\circ} \mathrm{C}, 1 \mathrm{~min}$ at $72^{\circ} \mathrm{C}(40 \mathrm{PCR}$ cycles), and finally, $10 \mathrm{~min}$ at $72^{\circ} \mathrm{C}$. A second PCR was then conducted with nested oligonucleotides. The product of the first amplifying proto$\operatorname{col}(3-5 \mu \mathrm{l})$ was used as template to do a second PCR in a final volume of $25 \mu$ l. The PCR solution contained the following: PCR buffer $(10 \times)$ (Amersham Biosciences, Piscataway, NJ), $10 \mu \mathrm{M}$ dNTPs (Invitrogen), 1 U of TaqDNA polymerase (Amersham Biosciences), and 50 pmol of each oligonucleotide. The reaction was performed as follows: 2 min at $94^{\circ} \mathrm{C}$, $30 \mathrm{~s}$ at $94^{\circ} \mathrm{C}, 30 \mathrm{~s}$ at $55-58^{\circ} \mathrm{C}$, and $1 \mathrm{~min}$ at $72^{\circ} \mathrm{C}$ ( 35 PCR cycles). The specific oligonucleotides for each gene were custom-designed (Invitrogen) based on the indicated references. They were as follows: for VGAT (McIntire et al., 1997), sense and antisense as described (Lamas et al., 2001); nested (antisense), 5' -TGATCTGGGCCACATTGACC-3'; dynorphin (Glasgow et al., 1999), sense, 5' -GAAGTGACAAACAGCGCTACAC-3'; antisense, 5'-TGCAACCTCAGAGGGGATCACAAG-3'; nested (sense), 5' -ACTGCCATAGGGGGATTTGGTAGC-3'; VGlut-1 (Ziegler et al., 2002), sense, 5' -ACGTGAACCACTTGGACATC-3'; antisense, 5' -CAAGAGGCAGTTGAGAAGGA-3'; nested, 5' -CAGTACGTGTTCCTCATAGC-3'.

The products were visualized by electrophoresis in agarose gels (1.5\%) with ethidium bromide. The expected weight of each final PCR product is as follows: VGAT, $250 \mathrm{bp}$; VGlut-1, $450 \mathrm{bp}$; and dynorphin $200 \mathrm{bp}$. As control experiments, we conducted multiple sham experiments in which the surrounding bath solution was collected and processed in parallel. Also, we did not detect the expression of mRNA in cells from which we omitted the reverse transcriptase from the RT reaction (see Fig. 2D).

Immunohistological procedures. The immunohistological procedure started $3 \mathrm{~h}$ after the treatment in vitro. For detection of $\mathrm{GAD}_{67}, \mathrm{GAD}_{65}$, calbindin, glutamate, and GABA immunoreactivity, the cultures were fixed for $10 \mathrm{~min}$ in $4 \%$ paraformaldehyde, rinsed with PBS, and exposed to a droplet of PBS with $0.3 \% \mathrm{H}_{2} \mathrm{O}_{2}$. After rinsing twice in PBS, they were 
incubated in $10 \%$ horse serum (Invitrogen), $1 \%$ gelatin (Sigma), and $0.1 \%$ Tween 20 (Sigma). The cells were then incubated in the presence of the primary antibodies [glutamate at 1:100, $\mathrm{GAD}_{67}$ at $1: 500, \mathrm{GAD}_{65}$ at 1:500, calbindin at 1:500 (Chemicon, Temecula, CA), and GABA at 1:100 (Sigma)] in PBS and horse serum (5\%) during $18 \mathrm{~h}$. After rinsing, they were incubated in the presence of an appropriate secondary biotinylated IgG (1:500; Jackson ImmunoResearch, West Grove, PA) and processed with the ABC Kit (Vectastain; Vector Laboratories, Burlingame, CA) for $1 \mathrm{~h}$ at room temperature. The avidin-biotin complex was developed with diaminobenzidine [10 mg/25 ml PBS (10 mM); Sigma] for $10 \mathrm{~min}$ and contrasted with nickel sulfate (30\%). In some experiments, we coupled the second antibody to the fluorescein-streptavidin complex (1:200; Vector Laboratories) or Texas Red (1:200; Vector Laboratories) to obtain immunofluorescent preparations. Microscopical observations and photomicrographs were done with an Axiovert microscope (Zeiss) with appropriate digital photographic equipment or with a confocal microscope (MRC 600; Bio-Rad, Hercules, CA). Granule cells and interneurons were identified, counted and photographed in three $1 \mathrm{~cm}^{2}$ coverslips per experiment. Thus, $n$ in Results represents the number of independent experiments, unless we specify otherwise. Statistical comparisons were assessed with one-way ANOVA and the post hoc Tukey tests. Difference was considered significant if $p<0.05$.

\section{Results}

Electrophysiological characterization of synaptic responses provoked by GC activation in hippocampal slices

Before the preparation of the cultures, we characterized the synaptic responses that DG activation produced in CA3 pyramidal cells. The characteristics of these synaptic responses have been thoroughly described previously (Gutiérrez et al., 2003; RomoParra et al., 2003). In brief, activation of the GCs in slices from 15 -d-old rats produced sequences of EPSPs and IPSPs in pyramidal cells of CA3. The perfusion of NBQX and APV blocked the EPSP and isolated a bicuculline-sensitive IPSP with the same onset latency as the control EPSP, whereby the mean latency difference of the EPSP and the IPSP $(0.13 \pm 0.08 \mathrm{~ms})$ was consistent with a monosynaptic contact (data not shown). These results were obtained in 60 of 60 cells studied. In contrast, in slices from adult naive rats, the perfusion of glutamate receptor antagonists blocked all synaptic responses in 80 of 80 cells recorded (Fig. $1 \mathrm{~A}$ ). When slices were obtained from rats having had one or more seizures or from five naive slices stimulated with a kindling-like protocol in vitro (Gutiérrez, 2002), pyramidal cells recorded in the presence of glutamate receptor blockers responded with a fast IPSP after GC activation $(n=80)$. Finally, we recorded from slices obtained from six adult naive rats, one-half of which were incubated in BDNF $(100 \mathrm{ng} / \mathrm{ml})$ and one-half in BDNF plus K252a for $30 \mathrm{~min}$ before the recordings commenced. Before and after these treatments, we stimulated the DG and recorded field potentials in CA3 to assess whether any epileptogenic activity was induced. Neither changes in the waveform of the population responses nor spontaneous or evoked epileptiform activity were found after the BDNF treatment (Fig. 1C). Granule cell activation in the BDNF-treated slices produced monosynaptic GABAergic responses in 21 of $25 \mathrm{CA} 3$ pyramidal cells, in the presence of glutamate receptor antagonists (Fig. 1 B). In contrast, in 20 of 20 cells from slices incubated in BDNF plus K252a, glutamate receptors antagonists blocked all synaptic responses (Fig. $1 D$ ). To corroborate the origin of the responses, we routinely tested the effect of the group III mGluR agonist L-AP-4 $(1 \mu \mathrm{M})$ (Fig. $1 E)$, which strongly inhibits the IPSP evoked by GC activation (Gutiérrez, 2000, 2002; Kasyanov et al., 2004).
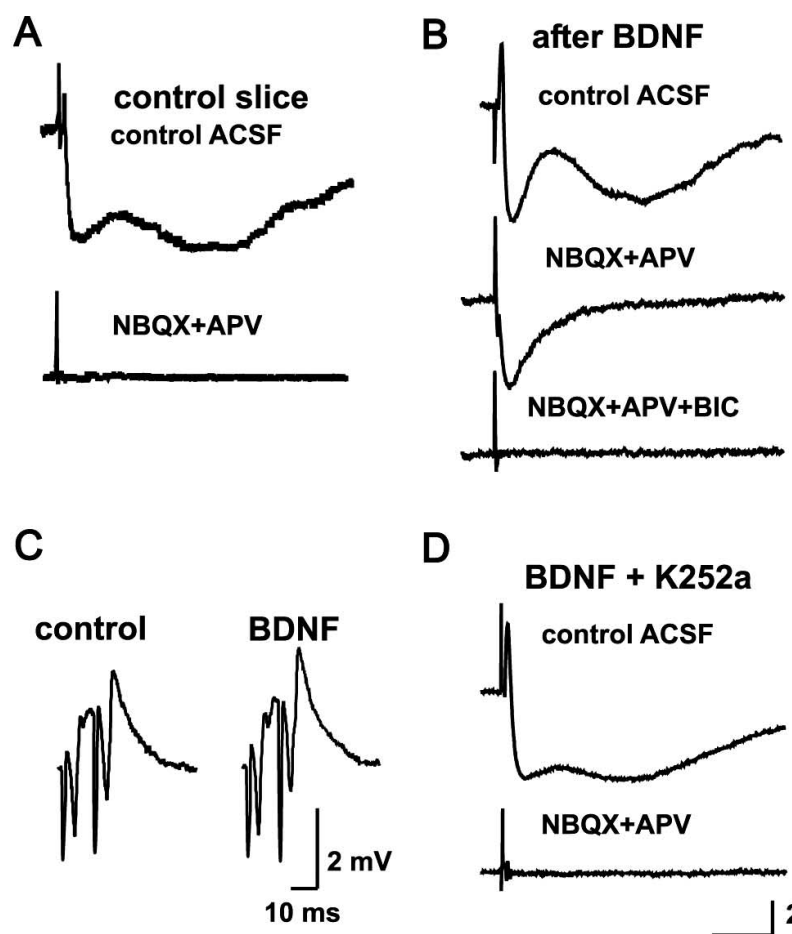

D
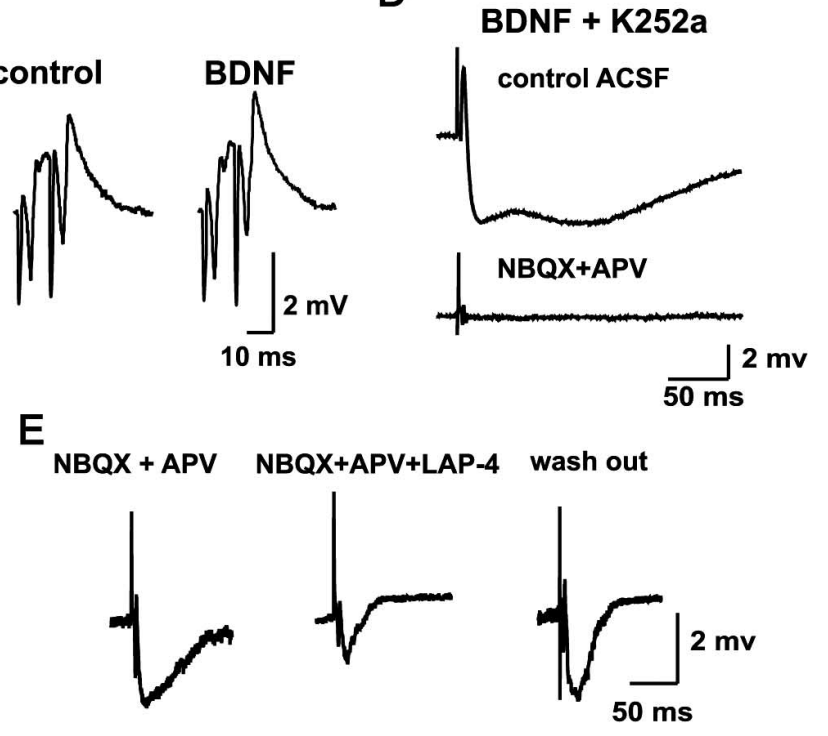

Figure 1. Mossy fiber monosynaptic GABAergic transmission can be detected when $\mathrm{GCS}$ express the markers of the GABAergic phenotype. $A$, Synaptic responses recorded in CA3 pyramidal cells from naive slices are blocked by the perfusion of the ionotropic glutamate receptors antagonists NBQX and APV. $\boldsymbol{B}$, In contrast, in preparations exposed to 30 min of BDNF (or to synaptic or direct activation in vivo and in vitro), mossy fiber stimulation provokes bicucullinesensitive monosynaptic IPSPs in the presence of NBQX and APV. C, BDNF treatment does not induce hyperexcitability, as assessed by field potential responses of CA3 to DG stimulation. $D$, The Trk receptor inhibitor K252a prevents the effect of BNDF, described in $\boldsymbol{B}$. $\boldsymbol{E}$, The pharmacologically isolated monosynaptic GABAergic responses are depressed by L-AP-4, a group III mGluR agonist. All traces are an average of six evoked responses. BIC, Bicuculline; LAP-4, L-AP-4.

\section{Electrophysiological characterization of GCs in} culture conditions

Granule cells were characterized by a spherical or oval-shaped body (mean diameter, $8.3 \pm 1.2 \mu \mathrm{m}$; measured from a random sample of $n=68$ ), usually with a dendritic process. In contrast, DG interneurons had a round soma larger than GCs $(12.7 \pm 2.6$ $\mu \mathrm{m}$; measured from a random sample of $n=30$ ), usually with several processes (Fig. 2). Granule cells had a resting membrane potential of $-65 \pm 1 \mathrm{mV}$, had an input resistance of $282 \pm 25$ $\mathrm{M} \Omega(n=50$; mean \pm SEM $)$, and fired a single action potential during a depolarizing DC pulse, whereas interneurons had a resting membrane potential of $-60 \pm 2 \mathrm{mV}$, had an input resistance of $325 \pm 31 \mathrm{M} \Omega(n=20$; mean \pm SEM $)$, and fired action potentials for as long as the cell was depolarized, without accommodation. The action potentials of the GCs were followed by an afterhyperpolarization and a short depolarizing component (Fig. $2 A_{1}$ ), whereas the action potentials of the interneurons were followed by a hyperpolarizing component (Fig. $2 B_{1}$ ). Taking to- 
gether the anatomical and electrophysiological characteristics, we could determine a GCs/interneuron ratio of $88 / 12 \%$ in our cultures.

\section{Single-cell RT-PCR}

All GCs from adult naive rats $(n=30)$ expressed mRNAs of VGlut-1 and dynorphin, and $45 \%$ also coexpressed a barely detectable band of VGAT mRNA (Figs. $\left.2 A_{2}, 3 A, E, F\right)$. In contrast, all GCs from 15 -d-old rats $(n=30)$ expressed mRNAs of VGlut-1, dynorphin, and VGAT (Figs. $\left.2 A_{2}, 3 E, F\right)$. For control purposes, we included electrophysiologically identified interneurons of the DG and acutely isolated CA3 pyramidal cells in our analysis (Fig. 2). Interneurons expressed mRNA of VGAT but not of dynorphin or VGlut1 $(n=10)$ (Fig. $\left.2 B_{2}\right)$, and pyramidal cells expressed mRNA of VGlut-1 $(n=10)$ (Fig. $2 C_{2}$ ) but not of VGAT or dynorphin. All GC cultures prepared from animals having had one or more seizures in vivo expressed VGlut-1, dynorphin, and VGAT mRNAs $(n=25)$ (Fig. $3 B, E)$.

To assess the effect of a depolarizing stimulus on the expression of the vesicular transporters transcripts in control adult cultures, we exposed them to KA in the presence and absence of antagonists of glutamate receptors and calcium channels. Three hours after the exposure to KA, 15 of 15 GCs coexpressed VGAT and VGlut-1 mRNAs (Fig. $3 C_{1}, E$ ). The KA-induced expression of VGAT mRNA $(n=10)$ could be prevented by the addition of NBQX and APV to the incubation medium (Fig. $\left.3 C_{2}, E\right)$ or by using a $\mathrm{Ca}^{2+}$-free, EGTAcontaining incubation medium (Fig. $\left.3 D_{1}, E\right)$. In BDNF-treated cultures, 16 of 24 GCs coexpressed VGAT mRNA and VGlut-1 mRNA (Fig. 3D, E). A densitometric analysis of the VGAT mRNA/ VGlut-1 mRNA ratio for each cell showed that the level of expression of VGAT mRNA was significantly higher in BDNFtreated cultures compared with KAtreated cultures (Fig. $3 F$ ). Also, the ratio of VGAT mRNA/VGlut-1 mRNA expression in 15-d-old rats was significantly higher than that of the control adult GCs expressing VGAT mRNA. In contrast, although all KA-treated adult GCs expressed VGAT mRNA, its expression was not significantly higher than that of the control GCs expressing this transcript (Fig. $3 F$ ).

\section{Immunohistological determination of the phenotype of adult} GCs in culture

With our isolation procedure, we obtained a cell density of $57 \pm$ 8 cells/field ( $n=2381 \mathrm{~cm}^{2}$ fields). From these, the number of GCs per field was $50 \pm 3$ and of interneurons was $7 \pm 4$ in the adult rat preparation. In the 15 -d-old rat preparations, the num-
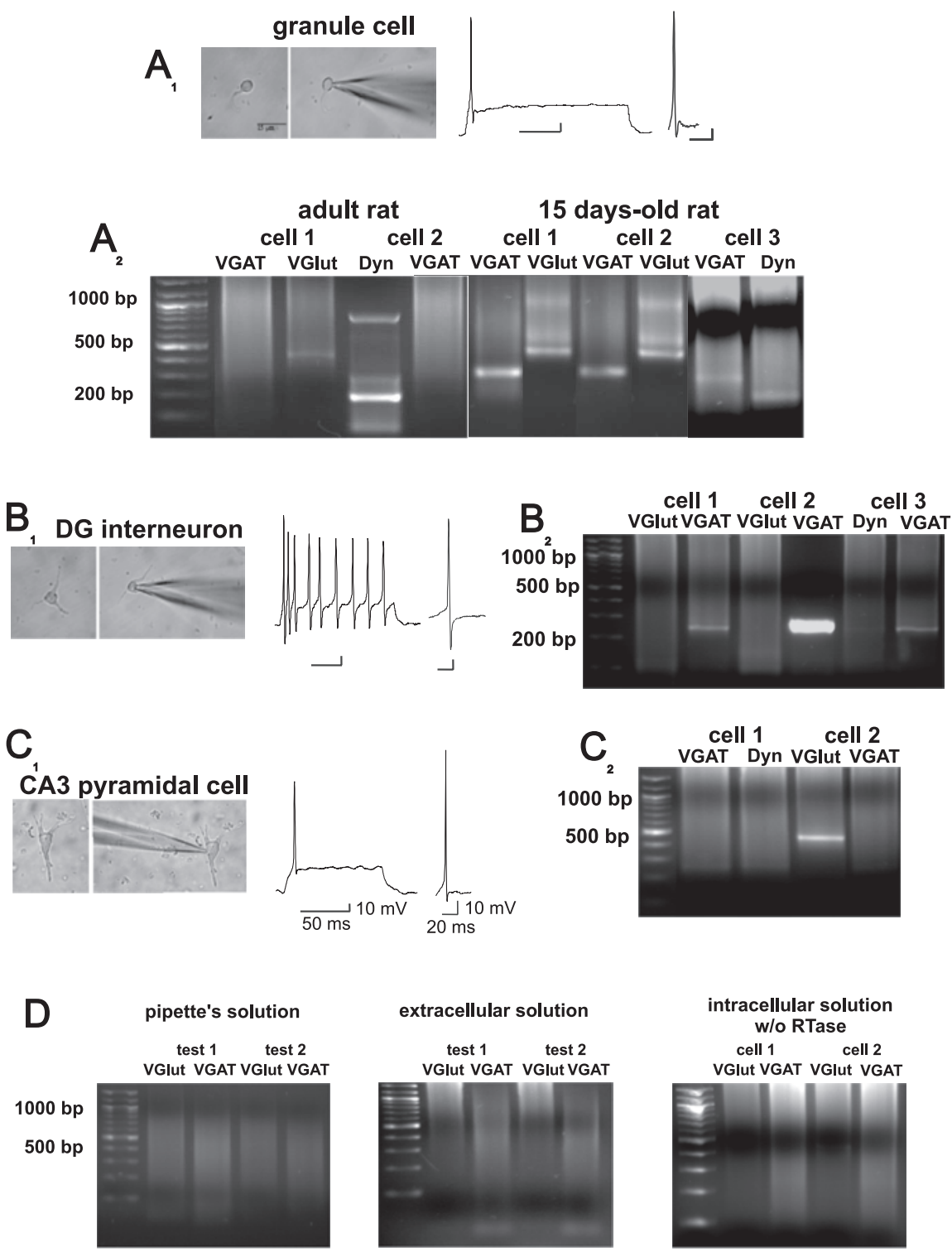

Figure 2. Developing GCS coexpress VGAT, VGlut-1, and dynorphin (Dyn) mRNAs. Whole-cell recordings in GCS $\left(\boldsymbol{A}_{1}\right)$, DG interneurons $\left(\boldsymbol{B}_{1}\right)$, and CA3 pyramidal cells $\left(\boldsymbol{C}_{\boldsymbol{1}}\right)$ in current-clamp mode permit their identification by the characteristic firing pattern during a depolarizing pulse and by the morphology of their action potentials. $A_{2}$, Single-cell RT-PCR of two adult GCS shows the presence of VGlut-1 and Dyn mRNAs but not of the VGAT transcript. In contrast, three GCs cultured from 15-d-old rats whereas $C A 3$ pyramidal cells $\left(\boldsymbol{C}_{1}, \boldsymbol{C}_{2}\right)$ expressed VGlut- 1 but not VGAT or Dyn mRNAs. $\boldsymbol{D}$, Single-cell RT-PCR control experiments. 列 solution (middle) and after amplification of the contents of the cells in the absence of reverse transcriptase (RTase) (right). Calibration for $\boldsymbol{A}_{\boldsymbol{1}}$ and $\boldsymbol{B}_{1}$ as in $\boldsymbol{C}_{\boldsymbol{1}}$.

ber of GCs per field was $52 \pm 10$ and of interneurons was $6 \pm 2$ ( $n=18$ fields). Because we electrophysiologically characterized a large number of cells, we could later reliably identify whether they were interneurons or GCs. However, additional confirmation of the phenotype was done by determining their immunoreactivity to calbindin and glutamate, and by determining the coexpression of glutamate and $\mathrm{GAD}_{67}$ or GABA (Fig. 4). In GCs of 15-d-old rats, $93 \pm 2 \%(n=3)$ coexpressed GABA-immunoreactive (IR) and glutamate-IR, $78 \pm 1 \%(n=3)$ (Fig. $4 A$ ) were $\mathrm{GAD}_{67}-\mathrm{IR}$, and $37 \pm 2 \%(n=3)$ were $\mathrm{GAD}_{65}$-IR (Fig. $\left.5 A\right)$. In cultures from adult rats, $95 \%(n=3)$ of the identified GCs were to calbindin, and $100 \%$ to glutamate, whereas $41 \pm 7 \%(n=3)$ coexpressed glutamate and $\mathrm{GAD}_{67}-\mathrm{IR}, 19 \pm 5 \%(n=3)$ were $\mathrm{GAD}_{65}-\mathrm{IR}$ and 

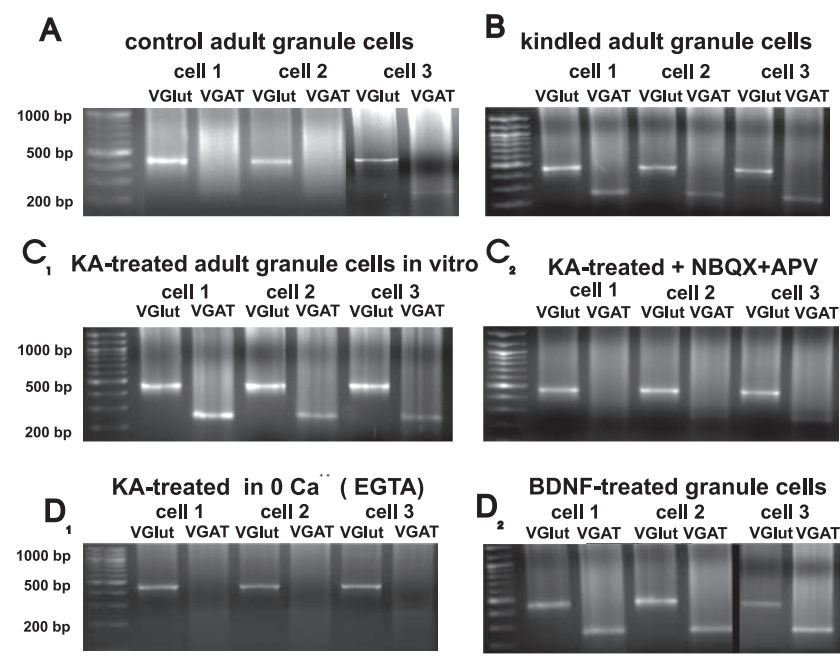

E
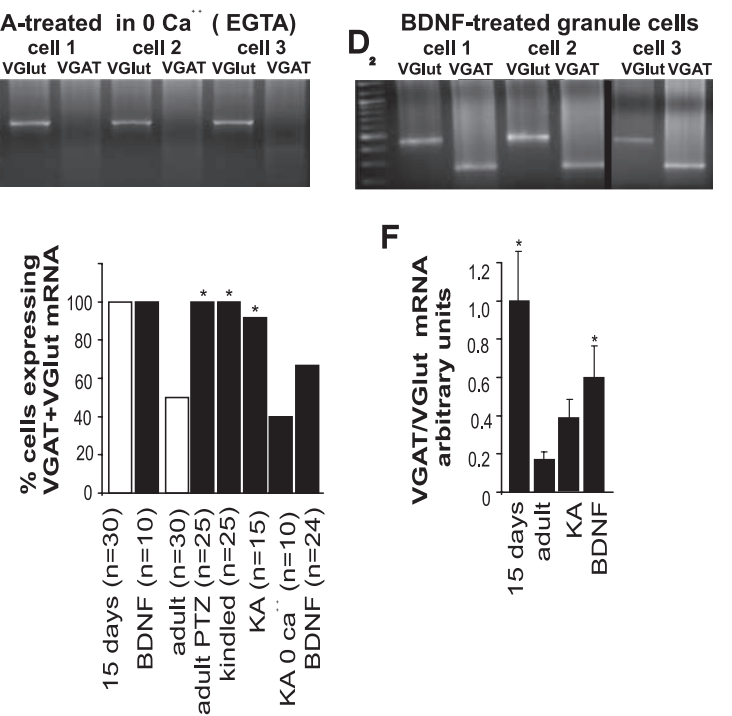

F

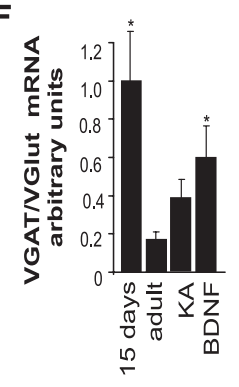

Figure 3. Granule cells cultured from epileptic rats, and from adult naive rats exposed to KA or BDNF, coexpress VGAT and VGlut-1 mRNA. $\boldsymbol{A}$, Control adult GCs express VGlut- 1 and some express barely detectable levels of VGAT mRNA (cell 3). $\boldsymbol{B}$, In contrast, all GCs cultured from kindled rats coexpress VGlut and VGAT mRNA. $\boldsymbol{C}_{1}$, KA-treated GC cultures coexpress VGlut-1 and VGAT mRNAs, whereby the expression of the latter is prevented by coincubation of the cells with KA and glutamate receptor blockers $\left(\boldsymbol{C}_{2}\right)$ or calcium-free medium $\left(\boldsymbol{D}_{1}\right)$. $\boldsymbol{D}_{2}$, Incubation of adult $\mathrm{GC}$ cultures with BDNF produces an upregulation of the expression of VGAT mRNA. $\boldsymbol{E}$, Summary of the results of the single-cell RT-PCR experiments showing the percentage of adult GCs that coexpressed VGlut-1 and VGAT mRNA under the different experimental conditions. *Significant statistical difference obtained by $\chi^{2}$ test with respect to adult, control at $p<0.05$ ( $n=$ number of cells). $\boldsymbol{F}$, Densitometric analysis of VGAT mRNA/VGlut-1 mRNA expression ratio under different experimental conditions. Note that the densitometric measurements included different numbers of cells in each condition, as shown in $\boldsymbol{E}$. Significant statistical difference obtained by one-way ANOVA at $p<0.05$. Error bars indicate SE.

$69 \pm 2 \%(n=3)$ were GABA-IR. In contrast, $100 \%$ of the identifiable interneurons were $\mathrm{GAD}_{65^{-}}, \mathrm{GAD}_{67^{-}}$, and GABA-IR. We contrasted these results with a set of experiments in which the slicing and dissociation of GCs for the cultures were done in the presence of TTX $(1 \mu \mathrm{M})$. In these conditions, $31 \pm 4 \%(n=3)$ of GCs coexpressed glutamate and $\mathrm{GAD}_{67}$-IR and $27 \pm 3 \%(n=3)$ GABA-IR (Figs. $4 B, 5 A, B$ ). These results indicate that the expression of GABAergic markers can occur in the GCs by the sole isolation procedure and overnight culture. Thus, the subsequent preparation of the cultures was performed in the presence of TTX. We then analyzed GC cultures prepared from in vitro kindled hippocampal slices $(n=4)$ and from rats having had five kindled seizures in vivo $(n=4)$. Under these conditions, a strong $\mathrm{GAD}_{67}$-IR was found in $99 \%$ of the cultured cells, whereas no difference was observed in $\mathrm{GAD}_{65}$-IR expression (35\%), compared with control preparations.
Activation of glutamate, but not of GABA receptors, induces the expression of the GABAergic markers in adult GC cultures To explore the effect of the activation of glutamate and GABA receptors on the expression of GABAergic markers in adult GC cultures, they were exposed to either KA or GABA (30 min) and fixed $3 \mathrm{~h}$ later to conduct immunohistological studies. After KA exposure, $76 \pm 4 \%$ of GCs coexpressed $\mathrm{GAD}_{67}$-IR and glutamate $(n=3)$, whereas $75 \pm 9 \%$ were GABA-IR (Figs. $4 B, C, 5)$. The percentage of $\mathrm{GAD}_{65}$-IR GCs was $22 \pm 8 \%$, which was not different from control conditions $(n=3)$ (Fig. 5A). When GCs from 15 -d-old rats were exposed to KA, the percentage of cells expressing $\mathrm{GAD}_{67}(81 \pm 3 \% ; n=3), \mathrm{GAD}_{65}(26 \pm 3 \% ; n=3)$, or GABA $(97 \pm 1 \% ; n=3)$ was not modified compared with the control condition (Fig. 5A). The immunoreactivity to $\mathrm{GAD}_{67}$ and GABA in the KA-treated adult GC cultures was prevented if NBQX plus APV $(n=3)$, cycloheximide $(n=3)$, or $\mathrm{NiCl}_{2}(n=2)$ was present during KA exposure (Figs. $4 C, 5 B$ ).

Exposure of the GCs to GABA alone $(n=3)$ or in the presence of $\mathrm{GABA}_{\mathrm{A}}$ and $\mathrm{GABA}_{\mathrm{B}}$ receptor antagonists (bicuculline and CGP55845A, respectively; $n=2$ ), or of the uptake blocker, nipecotic acid $(n=2)$, did not produce any change in the number of GABA- and $\mathrm{GAD}_{67}$-IR cells, with respect to control conditions (Fig. 5B).

Brain-derived neurotrophic factor induces the expression of GABAergic markers in adult GC cultures

Exposure of the cultures to BDNF (100 ng/ml) for $30 \mathrm{~min}$ in serum-free medium produced a significant increment of $\mathrm{GAD}_{67^{-}}$ IR, whereas the expression of GABA-IR was not significantly different with respect to control conditions. The percentage of cells that expressed GABA after BDNF incubation was $39 \pm 6 \%(n=$ 3 ), but $76 \pm 8 \%$ were found to coexpress glutamate and $\mathrm{GAD}_{67}$. The effect of BDNF was partially dependent on depolarization, because TTX partially prevented its effect. In these conditions, the percentage of GCs with $\mathrm{GAD}_{67}-\mathrm{IR}$ was $44 \pm 10 \%(n=5)$, and GABA-IR, $51 \pm 10 \%(n=5)$ (Figs. $4 D, 5 B)$. Interestingly, adding the tyrosine kinase inhibitor with high specificity for the Trk family, K252a, further decreased the number of GABA-IR GCs to $27 \pm 6 \%(n=5)$, but its effect on $\mathrm{GAD}_{67}$-IR was not different from that observed with TTX alone ( $50 \pm 5 \% ; n=2)$. The percentage of GCs that were $\mathrm{GAD}_{67}$-IR in the presence of the PKC inhibitor $\mathrm{H} 7$ was $24 \pm 4 \%(n=3)$ (Figs. $4 D, 5 B)$. In GC cultures from 15 -d-old rats, in which GAD-IR is highly expressed (78\%), BDNF further increased the GAD-IR GCs to $96 \%$. These results show that BDNF has a GABA phenotype inductor, but not suppressor, effect.

\section{Discussion}

In this work, we show that GC cultures prepared from developing rats normally express a dual glutamatergic/GABAergic phenotype, whereas those prepared from adult rats mainly express a glutamatergic-only phenotype. However, GC cultures prepared from epileptic rats or from slices of naive rats, which were either subjected to strong synaptic stimulation in situ or incubated in the presence of BDNF, coexpressed the markers of the glutamatergic and GABAergic phenotypes. Interestingly, adult, fully differentiated, dissociated GCs in cultures prepared from naive rats can be induced to express a GABAergic phenotype by activation of ionotropic glutamate and neurotrophin receptors. The depolarization-dependent expression of the GABAergic phenotype depends on calcium entry and on protein synthesis. Importantly, the GC cultures that expressed the dual glutamatergic/ GABAergic phenotype were prepared from slices in which we 


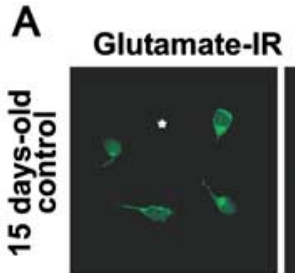

B Glutamate-IR
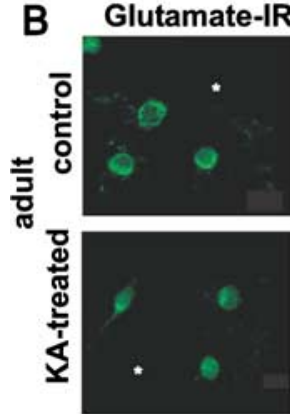

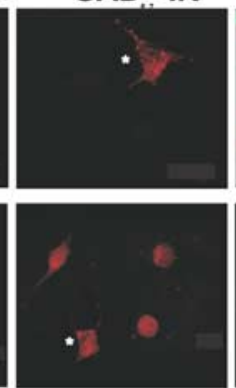

GABA-IR

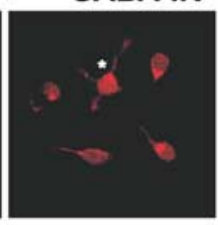

GAD -IR

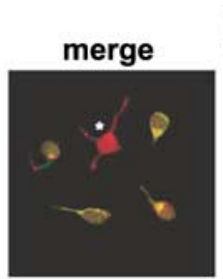

C

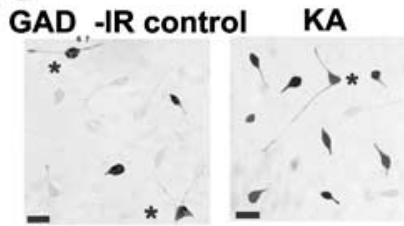

$\overline{G A B A-I R}$ control

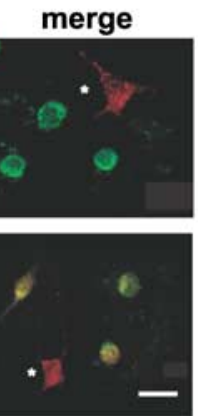

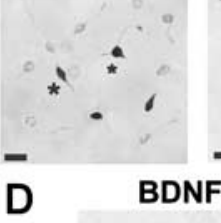

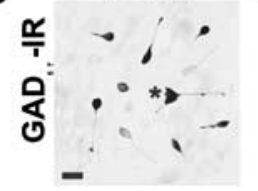

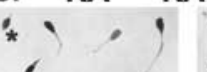

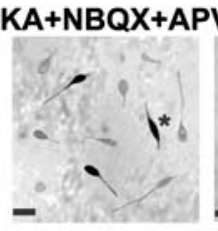

$K A+N B Q X+A P V$

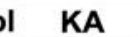

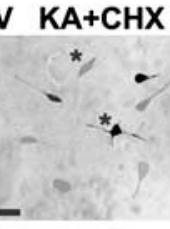

$\mathrm{KA}+\mathrm{CHX}$
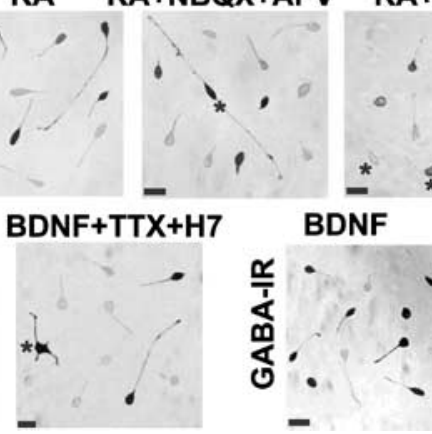

BDNF

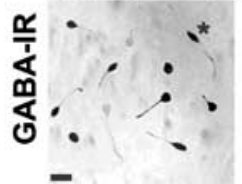

$\mathrm{KA}+\mathrm{NiCl}$

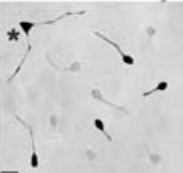

$\mathrm{KA}(0 \mathrm{Ca})$

Figure 4. Immunocytochemical determination of glutamate, $\mathrm{GAD}_{67}$, and $\mathrm{GABA}$ in cultured $\mathrm{GCS}$. $A$, Confocal images of short-term cultures of $\mathrm{GCS}$ and interneurons (asterisks) of a 15 - $d$-old rat show the coexpression of glutamate-IR and $G A B A-I R$ in $G C s . B$, In cultures from adult rats, $G C$ s express glutamate-IR but not $G A B A$ ergic markers unless they are exposed to $K A$, whereby $G A D_{67}-I R$ and glutamate-IR colocalize. C, Immunocytochemical determinations of the GABAergic markers after different treatments. Interneurons can be clearly differentiated and are indicated by asterisks. The number of $\mathrm{GCs}$ expressing $\mathrm{GAD}_{67}$ and $\mathrm{GABA}$ was increased by the exposure of the cultures to 30 min of $\mathrm{KA}$. The presence of glutamate receptor antagonists, or of $\mathrm{Na}^{+}$and $\mathrm{Ca}^{2+}$ channel blockers, prevented the expression of the GABAergic markers in the GCs. D, BDNF upregulated the GABAergic markers in GCs, and this effect was prevented by the tyrosine kinase inhibitor with high specificity for the Trk family, K252a. Scale bars: $\boldsymbol{B}$ (for $\boldsymbol{A}, \boldsymbol{B}), 15 \mu \mathrm{m} ; \boldsymbol{C}, \boldsymbol{D}, 20 \mu \mathrm{m}$.

first electrophysiologically corroborated that GC stimulation provoked monosynaptic glutamatergic, and mGluR-sensitive GABAergic responses in pyramidal cells of area $\mathrm{CA} 3$ in the presence of glutamate receptor antagonists.

Although we provided evidence suggesting the presence and activity-dependent upregulation of VGAT mRNA in the GCs (Lamas et al., 2001; Gutiérrez et al., 2003), our previous experiments were done using DG homogenates. By using single-cell RT-PCR, we now provide direct unequivocal evidence of its presence in developing GCs, of its activity-dependent upregulation in adults in vivo, and of its induction by the activation of glutamate and TrkB receptors in vitro. Moreover, the simultaneous detection of VGAT and VGlut-1 and/or dynorphin mRNAs confirms the identity of the GCs. Our present findings, and those showing that some GABAcontaining neurons do not contain VGAT (Chaudhry et al., 1998), suggest the existence of a yet-unidentified GABA transporter.

The mechanism that underlies the

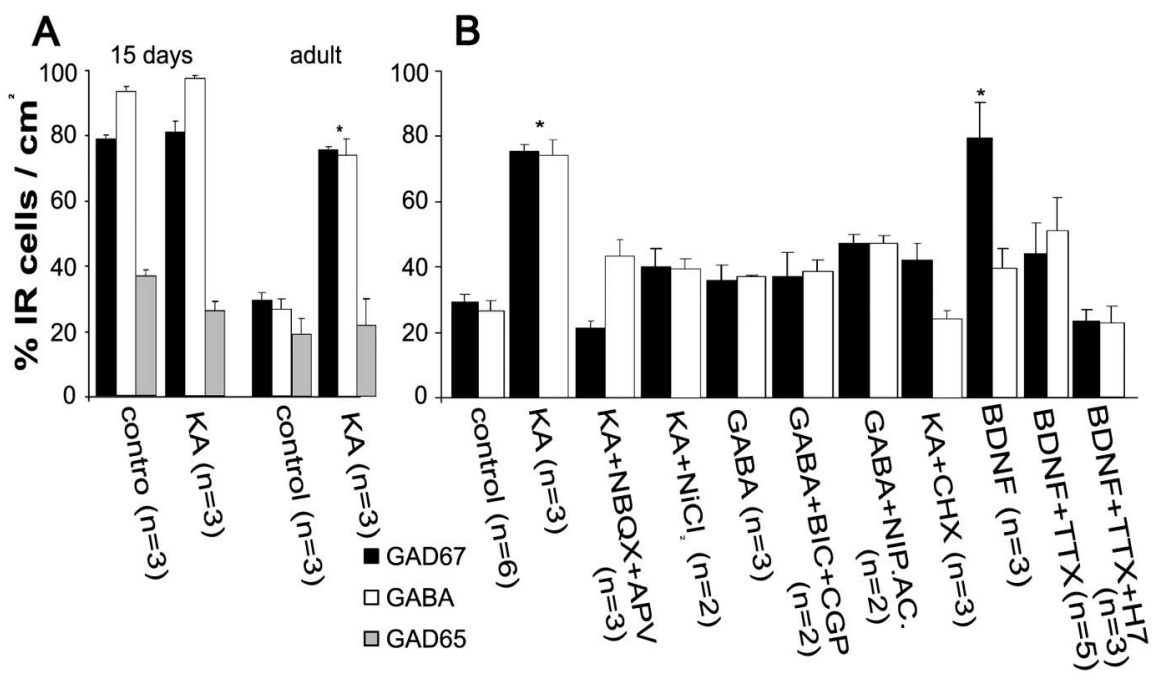

Figure 5. Percentage of cultured GCs expressing the GABAergic markers in control conditions and after the different experimental treatments. $A$, Developing $G C$ s express the GABAergic markers in control conditions and in the presence of KA. Whereas the expression of $\mathrm{GAD}_{65}$ is not modified, $G A B A$ and $\mathrm{GAD}_{67}$ are strongly downregulated in adult $\mathrm{GCs}$ and upregulated by $K A$ treatment. $B$, The effects of $K A$ are prevented in the presence of glutamate receptor antagonists and protein synthesis or calcium channel blockers. GABA receptor agonists and antagonists produce no effects. BDNF selectively increased the expression of $\mathrm{GAD}_{67}$. Whereas adding TTX partially prevented the effect of BNDF, the tyrosine kinase inhibitor with high specificity for the Trk family, K252a, and H7, a PKC inhibitor, totally blocked its effect. *Statistically significant difference with respect to the control group at $p<0.05$ (ANOVA). Error bars indicate SE. downregulation of the GABAergic phenotype in the GCs after completion of development is not known. It is possible that, as in embryonic neurons (Borodinsky et al., 2004), lack of excitation, or the change of GABA action from depolarization to hyperpolarization during development, can downregulate the GABAergic phenotype of the GCs. However, contrary to what happens in the embryonic neuronal population, activation of $\mathrm{GABA}_{\mathrm{A}}$ and $\mathrm{GABA}_{\mathrm{B}}$ receptors does not have any overt effect on the neurotransmitter choice in adult GCs. However, we confidently establish that the expression of the GABAer-

gic markers in adult GC cultures depends on prolonged increases of excitability, with the concomitant calcium entry, and on protein synthesis, as we have previously shown in GCs in situ (Gutiérrez, 2002). The role of calcium on phenotypic differentiation, and especially on the expression of the GABAergic phenotype, has been documented in developing cells (Watt et al., 2000; Ciccolini et al., 2003; Borodinsky et al., 2004).

This evidence suggests two possibilities: either activity upregulates the expression of GAD and GABA until the concentra- 
tion needed for GABA to be released is reached (Waagepetersen et al., 1999), or regardless of the intracellular levels of GAD and GABA, an unknown molecular trigger is put in play to enable the release of the available GABA. Whether the blockade of protein synthesis disrupts the synthesis of GAD, GABA, a vesicular transporter protein, or an unknown protein responsible for triggering the release of GABA needs additional investigation.

A second stimulus that we found to be involved in triggering the expression of the GABAergic phenotype in adult GCs is the activation of the TrkB receptor. Exposure of the hippocampal slices to BDNF produced the monosynaptic GABAergic signaling from the mossy fibers to emerge, and at the same time, it was highly effective in upregulating $\mathrm{GAD}_{67}-\mathrm{IR}$, and VGAT mRNA expression. In agreement with previous reports (Marty et al., 1996a,b), we show that BDNF is more effective than activity in upregulating mRNA and protein expression in the GCs. Neuronal activity is the main activator of GAD expression with neurotrophins differentially modulating transcription and translation in a context-dependent manner (Patz et al., 2003). Interestingly, this is the mechanism shown to underlie the maturation of the GABAergic phenotype in hippocampal interneurons (Marty et al., 1996a,b). Granule cells contain relatively high concentrations of BDNF and NGF, which can be released in vivo by the mossy fibers and dendrites to affect other mossy fibers or other somas, respectively (Blöchl and Thoenen, 1995; Lowenstein and Arsenault, 1996; Conner et al., 1997). Indeed, the dendritic targeting of BDNF mRNA and its translation to protein can account for the release of this neurotrophin to neighboring GC somata (Tongiorgi et al., 2004). This suggests that the ligand-receptor interaction occurs by means of an autocrine/paracrine mechanism.

BDNF mRNA expression is increased in adult rat forebrain after limbic seizures (Isackson et al., 1991), and it has been proposed that enhanced activation of TrkB receptors occurs in the hippocampus during limbic epileptogenesis (Binder et al., 1999). With our present data, we can propose that BDNF can transcriptionally regulate GABA-related genes in differentiated glutamatergic GCs in an activity-dependent manner. The localization of BDNF mRNA and its translation to protein in dendrites can be an effective means to activate neighboring GCs (Tongiorgi et al., 2004), and its anterograde transport would effectively provide a mechanism to release BDNF in terminals to produce additional neurotransmitter release by an increase in excitability (Altar and DiStefano, 1998; Elmer et al., 1998; Binder et al., 1999). Thus, sustained depolarization and release of BDNF (Thoenen, 1995) by excessive excitatory input onto GCs can underlie the expression of their GABAergic phenotype as an adaptive response (Gutiérrez and Heinemann, 2001; Gutiérrez, 2002, 2003). Indeed, BDNF promotes calcium influx (Berninger et al., 1993) and, as we previously showed, neurotransmitter release (Berzaghi et al., 1995; Thoenen, 1995). Importantly, it has been shown that BDNF can exert a rapid depolarization in hippocampal neurons by promoting $\mathrm{Na}^{+}$influx through TTX-insensitive channels, and this effect is prevented by K252a (Kafitz et al., 1999; Rose et al., 2003). In agreement with this, our data show that the GABA phenotype inductor effect of BNDF is completely prevented by K252a and H7, and partially by TTX. The intracellular pathway responsible for this effect, however, cannot be determined with our present data. Therefore, this inductor effect can be either induced by a tyrosine kinase-mediated intracellular cascade put in play by the activation of TrkB receptors leading to gene expression or by the immediate depolarizing effect of BDNF (Berzaghi et al., 1995; Kafitz et al., 1999), which, as in the case of KA, promotes calcium influx that triggers the expression of the GABAergic markers. It is interesting, however, that our electrophysiological data show that incubation of the slices in BDNF for 30 min does not induce hyperexcitability or epileptiform activity. Therefore, it is likely that the effects of BDNF are secondary to the induction of hyperexcitability.

The effects that we describe on adult GCs indicate that sustained abnormal electrical activity underlies BDNF regulation of neurotransmitter expression. As recently proposed, specific transcription factors might not lead to transmitter switches unless they are involved in programming electrical activity (Borodinsky et al., 2004). This idea is supported by data showing that BDNF selectively promotes GABAergic maturation (Yamada et al., 2002), that it switches the excitatory phenotype to an inhibitory phenotype in sympathetic neurons (Yang et al., 2002), and that it increases the number of GABAergic neurons and synapses differentiated from hippocampal stem cells and in primary cultures (Vicario-Abejón et al., 1998, 2000). From this, it is tempting to speculate that GCs can express a GABAergic phenotype, in addition to the glutamatergic one, probably as a reminiscence of the potentiality expressed by the hippocampal stem cells, which can be differentiated into excitatory and inhibitory neurons (VicarioAbejón et al., 2000). In the light of this evidence, our present and previous data (Gutiérrez et al., 2003) prompt the following question: do GCs born during adulthood also express a dual glutamatergic/GABAergic phenotype? This possibility needs to be disclosed, because it is known that developing postnatal GCs express a dual glutamatergic/GABAergic phenotype.

Finally, our data strongly suggest that the activity-dependent release of glutamate and BDNF from GCs underlies this plastic phenotypic expression in neighboring GCs in situ. We conclude that the expression of a dual phenotype in GCs, which are unique in terms of their continuing birth and death throughout life, is neither limited by a critical developmental period nor restricted by their insertion in their natural network. This property makes these cells potentially suitable for ex vivo differentiation and reinstallment in a custom-designed neural circuit equipped with an activity-sensitive phenotypic switch.

\section{References}

Altar CA, DiStefano PS (1998) Neurotrophin trafficking by anterograde transport. Trends Neurosci 21:433-437.

Ben-Ari Y, Tseeb V, Raggozzino D, Khazipov R, Gaïarsa JL (1994) gammaAminobutyric acid (GABA): a fast excitatory transmitter which may regulate the development of hippocampal neurones in early postnatal life. Prog Brain Res 102:261-273.

Bergersen L, Ruiz A, Bjaalie JG, Kullmann DM, Gundersen V (2003) GABA and GABAA receptors at hippocampal mossy fibre synapses. Eur J Neurosci 18:931-941.

Berninger B, Garcia DE, Inagaki N, Hahnel C, Lindholm D (1993) BDNF and NT-3 induce intracellular $\mathrm{Ca}^{2+}$ elevation in hippocampal neurones. NeuroReport 4:1303-1306.

Berzaghi MP, Gutiérrez R, Heinemann U, Lindholm D, Thoenen H (1995) Neurotrophins induce acute transmitter-mediated changes in brain electrical activity. Soc Neurosci Abstr 21:226.3.

Binder DK, Routbort MJ, McNamara JO (1999) Immunohistochemical evidence of seizure-induced activation of trk receptors in the mossy fiber pathway of adult rat hippocampus. J Neurosci 19:4616-4626.

Blöchl A, Thoenen H (1995) Characterization of nerve growth factor (NGF) release from hippocampal neurons: evidence for a constitutive and an unconventional sodium-dependent regulated pathway. Eur J Neurosci 7:1220-1228.

Borodinsky LN, Root CM, Cronin JA, Sann SB, Gu X, Spitzer NC (2004) Activity-dependent homeostatic specification of transmitter expression in embryonic neurons. Nature 429:523-530.

Chaudhry FA, Reimer R, Bellocchio EE, Danbolt NC, Osen KK, Edwards RH, Storm-Mathisen J (1998) The vesicular GABA transporter, VGAT, local- 
izes to synaptic vesicles insets of glycinergic as well as GABAergic neurons. J Neurosci 18:9733-9750.

Ciccolini F, Collins TJ, Sudhoelter J, Lipp P, Berridge MJ, Bootman MD (2003) Local and global spontaneous calcium events regulate neurite outgrowth and onset of GABAergic phenotype during neural precursor differentiation. J Neurosci 23:103-111.

Conner JM, Lauterborn JC, Yan Q, Gall CM, Varon S (1997) Distribution of brain-derived neurotrophic factor (BDNF) protein and mRNA in the normal adult rat CNS: evidence for anterograde axonal transport. J Neurosci 17:2295-2313.

Elmer E, Kokaia Z, Kokaia M, Carnahan J, Nawa H, Lindvall O (1998) Dynamic changes of brain-derived neurotrophic factor protein levels in the rat forebrain after single and recurring kindling-induced seizures. Neuroscience 83:351-362.

Glasgow E, Kusano K, Chin H, Mezey E, Young III WS, Gainer H (1999) Single cell reverse transcription-polymerase chain reaction analysis of rat supraoptic magnocellular neurons: neuropeptide phenotypes and high voltage-gated calcium channel subtypes. Endocrinology 140:5391-5401.

Gómez-Lira G, Trillo E, Ramírez M, Asai M, Sitges M, Gutiérrez R (2002) Expression of GABAergic transmission in the mossy fiber synapse coincides with the seizure-induced expression of GABA in mossy fiber synaptosomes. Exp Neurol 177:276-283.

Gutiérrez R (2000) Seizures induce simultaneous GABAergic and glutamatergic neurotransmission in the dentate gyrus-CA3 system. J Neurophysiol 84:3088-3090.

Gutiérrez R (2002) Activity-dependent expression of simultaneous glutamatergic and GABAergic neurotransmission from the mossy fibers in vitro. J Neurophysiol 87:2562-2570.

Gutiérrez R (2003) The GABAergic phenotype of the "glutamatergic" granule cells of the dentate gyrus. Prog Neurobiol 71:337-358.

Gutiérrez R, Heinemann U (2001) Kindling induces transient fast inhibition in the dentate gyrus-CA3 projection. Eur J Neurosci 13:1371-1379.

Gutiérrez R, Romo-Parra R, Maqueda J, Vivar C, Ramírez M, Morales MA, Lamas M (2003) Plasticity of the GABAergic phenotype of the "glutamatergic" granule cells of the rat dentate gyrus. J Neurosci 23:5594-5598.

Isackson PJ, Huntsman MM, Murray KD, Gall CM (1991) BDNF mRNA expression is increased in adult rat forebrain after limbic seizures: temporal patterns of induction distinct from NGF. Neuron 6:937-948.

Kafitz KW, Rose CR, Thoenen H, Konnerth A (1999) Neurotrophin-evoked rapid excitation through TrkB receptors. Nature 401:918-921.

Kasyanov AM, Safiulina VF, Voronin LL, Cherubini E (2004) GABAmediated giant depolarizing potentials as coincidence detectors for enhancing synaptic efficacy in the developing hippocampus. Proc Natl Acad Sci USA 101:3967-3972.

Lamas M, Gómez-Lira G, Gutiérrez R (2001) Vesicular GABA transporter mRNA expression in the dentate gyrus and in mossy fiber synaptosomes. Mol Brain Res 93:209-214.

Lehmann H, Ebert U, Löscher W (1996) Immunocytochemical localization of GABA immunoreactivity in dentate granule cells of normal and kindled rats. Neurosci Lett 212:41-44.

Leinekugel X, Medina I, Khalilov I, Ben-Ari Y, Khazipov R (1997) $\mathrm{Ca}^{2+}$ oscillations mediated by the synergistic excitatory actions of GABA(A) and NMDA receptors in the neonatal hippocampus. Neuron 18:243-255.

Li Y-X, Zhang Y, Lester HA, Schuman EM, Davidson N (1998) Enhancement of neurotransmitter release induced by brain-derived neurotrophic factor in cultured hippocampal neurons. J Neurosci 18:10231-10240.

Lowenstein DH, Arsenault L (1996) The effects of growth factors on the survival and differentiation of cultured dentate gyrus neurons. J Neurosci 15:1759-1769.

Marty S, Carroll P, Cellerino A, Castren E, Staiger V, Thoenen H, Lindholm D (1996a) Brain-derived neurotrophic factor promotes the differentiation of various hippocampal nonpyramidal neurons, including Cajal-Retzius cells, in organotypic slice cultures. J Neurosci 16:675-687.
Marty S, Berninger B, Carroll P, Thoenen H (1996b) GABAergic stimulation regulates the phenotype of hippocampal interneurons through the regulation of brain-derived neurotrophic factor. Neuron 16:565-570.

Marty S, Berzaghi MP, Berninger B (1997) Neurotrophins and activitydependent plasticity of cortical interneurons. Trends Neurosci 20:198-202.

McIntire SL, Reimer RJ, Schuske K, Edwards RH, Jorgensen EM (1997) Identification and characterization of the vesicular GABA transporter Nature 389:870-876.

Patz S, Wirth MJ, Gorba T, Klostermann O, Wahle P (2003) Neuronal activity and neurotrophic factors regulate GAD-65/67 mRNA and protein expression in organotypic cultures of rat visual cortex. Eur J Neurosci 18:1-12.

Ramírez M, Gutiérrez R (2001) Activity-dependent expression of GAD67 in the granule cells of the rat hippocampus. Brain Res 917:139-146.

Romo-Parra H, Vivar C, Maqueda J, Morales MA, Gutiérrez R (2003) Activity-dependent induction of multitransmitter signaling onto pyramidal cells and interneurons of hippocampal area CA3. J Neurophysiol 89:3155-3167.

Rose CR, Blum R, Pichler B, Lepier A, Kafitz KW, Konnerth A (2003) Truncated TrkB-T1 mediates neurotrophin-evoked calcium signalling in glia cells. Nature 426:74-78.

Sandler R, Smith AD (1991) Coexistence of GABA and glutamate in mossy fiber terminals of the primate hippocampus: an ultrastructural study. J Comp Neurol 303:177-192.

Schwarzer C, Sperk G (1995) Hippocampal granule cells express glutamic acid decarboxylase 67 after limbic seizure in the rat. Neuroscience 69:705-709.

Sloviter RS, Dichter MA, Rachinsky TL, Dean E, Goodman JH, Sollas AL, Martin DL (1996) Basal expression and induction of glutamate decarboxylase and GABA in excitatory granule cells of the rat and monkey hippocampal dentate gyrus. J Comp Neurol 373:593-618.

Thoenen H (1995) Neurotrophins and neuronal plasticity. Science 270:593-598.

Tongiorgi E, Armellin M, Giulianini PG, Bregola G, Zucchini S, Paradiso B, Steward O, Cattaneo A, Simonato M (2004) Brain-derived neurotrophic factor mRNA and protein are targeted to discrete dendritic laminas by events that trigger epileptogenesis. J Neurosci 24:6842-6852.

Vicario-Abejón C, Collin C, McKay RD, Segal M (1998) Neurotrophins induce formation of functional excitatory and inhibitory synapses between cultured hippocampal neurons. J Neurosci 18:7256-7271.

Vicario-Abejón C, Collin C, Tsoulfas P, McKay RD (2000) Hippocampal stem cells differentiate into excitatory and inhibitory neurons. Eur J Neurosci 12:677-688.

Waagepetersen HS, Sonnewald U, Schousboe A (1999) The GABA paradox: multiple roles as metabolite, neurotransmitter, and neurodifferentiative agent. J Neurochem 73:1335-1342.

Walker MC, Ruiz A, Kullmann DM (2001) Monosynaptic GABAergic signaling from dentate to CA3 with a pharmacological and physiological profile typical of mossy fiber synapses. Neuron 29:703-715.

Watt SD, Gu X, Smith RD, Spitzer NC (2000) Specific frequencies of spontaneous $\mathrm{Ca}^{2+}$ transients upregulate GAD 67 transcripts in embryonic spinal neurons. Mol Cell Neurosci 16:376-387.

Yamada MK, Nakanishi K, Ohba S, Nakamura T, Ikegaya Y, Nishiyama N, Matsuki N (2002) Brain-derived neurotrophic factor promotes the maturation of GABAergic mechanisms in cultured hippocampal neurons. J Neurosci 22:7580-7585.

Yang B, Slonimsky JD, Birren SJ (2002) A rapid switch in sympathetic neurotransmitter release properties mediated by the $\mathrm{p} 75$ receptor. Nat Neurosci 5:503-504.

Ziegler DR, Cullinan WE, Herman JP (2002) Distribution of vesicular glutamate transporter mRNA in rat hypothalamus. J Comp Neurol 448: $217-229$. 